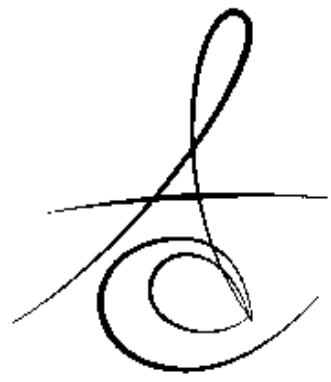

Makale Kodu/Article code: 1556

Makale Gönderilme tarihi: 21.02 .2014

Kabul Tarihi: 03.06.2014

\title{
SABİT PROTETİK RESTORASYONLARDA KULLANILAN GÜNCEL TASARIM VE ÜRETİM YÖNTEMLERİ
}

\author{
CURRENT DESIGN AND MANUFACTURING TECHNIQUES USED IN FIXED \\ PROSTHETIC RESTORATIONS
}

Yrd. Doç. Dr. Burcu KANAT ERTÜRK*

Doç. Dr. M. Erhan ÇÖMLEKOĞLU*
Prof.Dr. Mine DÜNDAR ÇÖMLEKOĞLU*

Prof. Dr. Mehmet Ali GÜNGÖR*

\section{ÖZET}

Özellikle posterior bölgede uygulanan sabit protetik restorasyonlarda, çiğneme kuvvetleri karşısında restorasyonun dayanıklıı̆ını arttırmak amacıyla üst yapı seramiği alt yapı ile desteklenmelidir. Gelişen teknoloji ve kullanılan materyallerdeki yenilikler ile, bilgisayar destekli tasarım/bilgisayar destekli üretim sistemleri günümüz protetik restorasyonlarda alt yapıların yanı sıra üst yapıların hazırlanmasında da kullanılmaktadır. Sabit protetik restorasyonlarda sıklıkla kullanılan alt yapı hazırlama yöntemleri geleneksel kayıp mum tekniği, eksiltme ve tabakalama esaslı ekleme yöntemleri iken; üst yapı hazırlama yöntemleri tabakalama, ısı-basınç ile şekillendirme ve bilgisayar destekli tasarım/bilgisayar destekli üretim sistemi ile elde edilen "dosya bölme" teknikleridir. Bu derlemede, sabit protetik restorasyonlarda kullanılan güncel alt yapı ve üst yapı hazırlama yöntemleri incelenmektedir.

Anahtar Kelimeler: Alt yapı hazırlama yöntemleri, üst yapı hazırlama yöntemleri, CAD/CAM

\section{GİRİŞ}

Sabit protetik restorasyonların okluzal kuvvetler karşısında yeterli mekanik dirence sahip olması, restorasyonların uzun ömürlü olmasını ve klinik başarısını etkileyen en önemli özelliklerden biridir. Ancak, kırılgan yapıdaki feldspatik porselenlerin gerilim stresleri karşısındaki dayanıklılıklarının yetersiz olması nedeniyle özellikle posterior bölgede uygulanan restorasyonlar, metal ya da yüksek dayanıklılıktaki seramik alt yapılar ile desteklenmelidir. ${ }^{1,2}$

\section{ABSTRACT}

Especially for the fixed prosthetic restorations in the posterior region, the veneering ceramic should be supported by the framework to increase the strength of the restoration against masticatory forces. By the improved technology and novelties in the used materials, computer aided design/computer aided manufacturing systems are used in the frameworks as well as in the veneering ceramics in contemporary prosthetic restorations. While the framework techniques frequently used in the fixed prosthetic restorations are lost-wax casting, subtractive and layered addivite techniques; methods used for the suprastructures are layering, pressing and the filesplitting technique obtained by computer aided design/computer aided manufacturing system. In this review, current framework and veneering techniques used in fixed prosthetic restorations are analyzed.

Keywords: Framework techniques, veneering techniques, CAD/CAM

Yüksek mekanik özellikleri ve başarılı uzun dönem klinik sonuçları ile "altın standart" olarak belirtilen metal destekli protetik restorasyonlar, günümüzde hala geniş kullanım alanı bulmaktadır. ${ }^{3}$ Bunun yanı sıra son zamanlarda zirkonya materyali; biyouyumluluğu, yüksek mekanik özellikleri, korozyona karşı dirençli olması, düşük plak birikimi, dişetinden metal yansımasının önlenmesi, düşük ısı ve elektrik iletkenliği gibi özellikleri nedeniyle tüm seramik restorasyonlarda alt yapı materyali olarak tercih edilmektedir. ${ }^{4}$ Ancak zirkonyanın opak olması, 'düşük sıcaklık bozunumu (low temperature degradation)" olarak da bilinen yaşlanması nedeniyle monoklinik

\footnotetext{
* Ege Üniversitesi Diş Hekimliği Fakültesi, Protetik Diş Tedavisi Anabilim Dalı
} 
Atatürk Üniv. Diş Hek. Fak. Derg.

J Dent Fac Atatürk Uni

Cilt:25, Sayı: 1, Yıl: 2015, Sayfa: 135-143

fazdaki artışa bağlı olarak mekanik özelliklerinin azalması ve yüzey işlemleri karşısında faz dönüşümünün tetiklenmesi gibi klinik olarak kontrol edilmesi olanaksız olan olumsuz özellikleri de bulunmaktadır. ${ }^{5}$ Ayrıca zirkonya alt yapılı restorasyonlarda en sık gözlenen komplikasyonun üst yapı seramiğinin alt yapıdan tabaka halinde (delaminasyon) ya da kırılarak ayrılması (chipping) olduğu bildirilmiştir. ${ }^{6,7}$

Zirkonya materyalinin diş hekimliğinde kullanılması ile bilgisayar destekli tasarım/bilgisayar destekli üretim (CAD/CAM) sistemlerinin gelişmesi de paralellik göstermiştir. CAD/CAM sistemleri günümüzde inley/ onley, kron/köprü, lamina, bireysel dayanak (abutment) gibi birçok tedavi seçeneğinde kullanılabilmektedir. Ayrıca sabit bölümlü protezlerde, istenilen kalınlığa sahip anatomik şekilli alt yapıların hazırlanmasına izin vermesinin yanı sıra "dosya bölme" (file splitting) yöntemi ile aynı anda alt yapı ve üst yapılar da elde edilebilmektedir. ${ }^{8-10}$ Gelişen teknoloji ile birlikte üst yapı materyallerinin içerikleri ve elde edilme yöntemleri de çeşitlilik göstermektedir. ${ }^{10}$ Günümüz diş hekimliğinde yaygın olarak kullanılan CAD/CAM tekniğine alternatif olarak, malzeme sarfiyatını engelleyerek üretimin daha hızlı gerçekleşmesini sağlayan ve üst üste tabaka ekleme prensibini benimseyen yöntemler de geliştirilmiştir. ${ }^{11}$ Çalışmamızda sabit protetik restorasyonların yapımında kullanılan güncel alt yapı ve üst yapı hazırlama yöntemleri ele alınacaktır (Tablo 1).

Tablo 1. Sabit protetik restorasyonlarda kullanılan güncel alt yapı ve üst yapı hazırlama yöntemleri

\begin{tabular}{|c|c|c|}
\hline \multirow{8}{*}{$\begin{array}{c}\text { Alt Yapı } \\
\text { Hazırlama } \\
\text { Yöntemleri }\end{array}$} & $\begin{array}{l}\text { Kayıp Mum } \\
\text { Tekniği }\end{array}$ & \\
\hline & \multirow[t]{2}{*}{$\begin{array}{l}\text { Eksiltme } \\
\text { Yöntemi } \\
\text { (Subtractive) }\end{array}$} & $\begin{array}{l}\text { Bilgisayar Destekli Tasarım } \\
\text { ve Üretim (CAD/CAM) } \\
\text { - Hasta başında } \\
\text { gerçekleşen klinik üretim } \\
\text { - Laboratuvarda üretim } \\
\text { - Üretim merkezlerinde } \\
\text { kullanılan merkezi üretim }\end{array}$ \\
\hline & & Kopya-Freze \\
\hline & \multirow{5}{*}{$\begin{array}{l}\text { Ekleme } \\
\text { Yöntemi } \\
\text { (Additive) }\end{array}$} & Stereolitografi (SLA) \\
\hline & & $\begin{array}{l}\text { Lazer Toz İşleme Teknikleri } \\
\text { - Selektif lazer } \\
\text { sinterleme (SLS) } \\
\text { - Selektif lazer eritme } \\
\text { (SLM) }\end{array}$ \\
\hline & & $\begin{array}{l}\text { Tabakalı Nesne Üretimi } \\
(\text { LOM) }\end{array}$ \\
\hline & & $\begin{array}{l}\text { Kaynaklı Yükleme Modelleme } \\
\text { (FDM) }\end{array}$ \\
\hline & & Mürekkep Baskı Tekniği \\
\hline \multirow{3}{*}{$\begin{array}{c}\text { Üst Yapı } \\
\text { Hazırlama } \\
\text { Yöntemleri }\end{array}$} & \multicolumn{2}{|c|}{ Fırça Yöntemi ile Tabakalama Tekniği } \\
\hline & \multicolumn{2}{|c|}{ Isı ve Basınç ile Şekillendirme Tekniği } \\
\hline & \multicolumn{2}{|c|}{ Dosya Bölme Tekniği } \\
\hline
\end{tabular}

KANAT ERTÜRK, DÜNDAR ÇÖMLEKOĞLU, ÇÖMLEKOĞLU, GÜNGÖR

\section{ALT YAPILARIN HAZIRLANMASI}

Sabit protetik restorasyonlarda alt yapılar, geleneksel kayıp mum tekniği ile elde edilebileceği gibi, günümüz diş hekimliğinde güncel olarak kullanılan eksiltme (subtractive) ve ekleme (additive) yöntemleri ile de hazırlanabilir. ${ }^{11}$

Alt yapılar, bilgisayar destekli tasarım ve üretim (CAD/CAM) ile kopya-freze yöntemlerinde eksiltme yöntemi kullanılarak elde edilirken; stereolitografi (SLA), seçici lazer sinterleme (SLS), kaynaklı yükleme modelleme (FDM), mürekkep baskı tekniği gibi tabakalama esaslı hızlı prototipleme yöntemleri kullanıldığında ekleme yöntemi ile üretilir. ${ }^{11}$

\section{KAYIP MUM TEKNİĞİ}

Mumlama yöntemi ilk olarak inley kavitenin mum ile doldurulması ve mumun sertleşmesi ardından döküm işleminin gerçekleştirilmesi ile 1891 yılında Martin tarafından altın inleylerin yapımında kullanılmıştır. ${ }^{12}$ Dr. Philbrook ise, 1896 yılında, ağız içinde şekillendirilen mum modelajın döküm kanallarına bağlanarak mumun uzaklaştırılması sonrasında hava basıncı altında altın alaşımının dökümünü geliştirmiştir. ${ }^{12}$

Günümüzde değerli ve değersiz metal alaşımlarından elde edilen alt yapıların hazırlanmasında yaygın olarak kullanılan kayıp mum tekniğinde, model üzerinde gerçekleştirilen mum modelaj revetmana alınır ve ön ısıtma fırınında elde edilen negatif boşluğa, eriyik alaşım materyalinin santrifüjlü döküm apareyinde dökülmesi ile alt yapılar elde edilir. ${ }^{13}$

\section{EKSİLTME YÖNTEMİ}

Günümüz diş hekimliğinde kullanılan CAD/CAM tekniğinin prensibi, eksiltme yöntemine dayanmaktadır. ${ }^{11}$ Eksiltme yönteminde, bilgisayar ortamında hazırlanan alt yapı tasarımı veya restorasyonun son formunda olan modelaj kopyası, üretici firmalar tarafından hazırlanan prefabrike bloklar kullanılarak kazıma cihazında elde edilir. Böylece geleneksel yöntemlerle üretimi zor olan karmaşık yapıdaki restorasyonlar, kısa sürede kolaylıkla elde edilebilir. Ancak kazıma işlemi sırasında, bloğun restorasyon dışında kalan bölümleri frezelenerek kullanılamaz hale geldiği için malzeme sarfiyatına neden olunur. ${ }^{11,14}$

\section{Bilgisayar Destekli Tasarım ve Üretim (CAD/CAM) Yöntemi}

Francois Duret tarafindan 1971 'de tanitılan CAD/CAM sistemi, preparasyon alanı ya da elde edilen 
model ölçüsünün bilgisayara aktarılması, elde edilen dijital veri üzerinde tasarımların gerçekleştirilmesi ve restorasyonun bu sistem için özel olarak geliştirilen seramik bloklardan kazınarak üretilmesinden oluşur. ${ }^{15}$

CAD/CAM sistemleri, yapısını oluşturan tarayıcl, tasarım ve kazıma ünitelerinin konumlarına bağı olarak 3 farklı üretim şekline sahiptir. ${ }^{16}$

a) Hasta başında gerçekleşen klinik üretim: CAD/CAM sisteminin tüm ögeleri klinikte yer alır. Ağız içi kamera ile elde edilen dijital ölçü üzerinde tasarım gerçekleştirilir ve kazıma ünitesinde restorasyon hazırlanır. Bu üretim şeklinin en büyük avantajı, restorasyonun tek seansta hasta ağzına uygulanabilmesidir. Günümüzde Cerec sistemi (Sirona, GmbH, Bensheim, Almanya) ve E4D (D4D Technologies, Richardson, Texas) bu gruba örnek olarak gösterilebilir $^{16}(\text { Resim } 1)^{17}$.

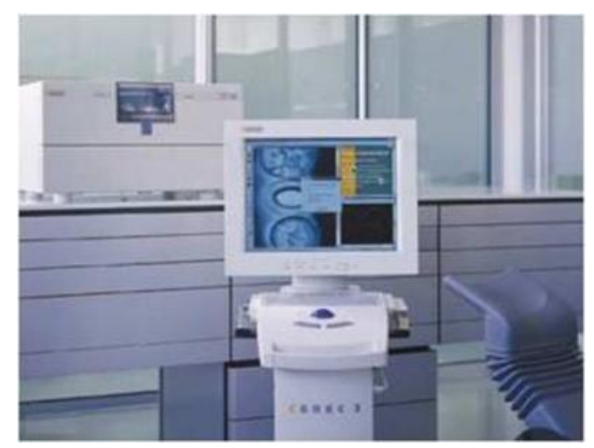

Resim 1. Cerec 3 sisteminin tarayıcı, tasarım ve kazıma üniteleri

b) Laboratuvarda üretim: Hekim, preparasyon alanını içeren geleneksel ölçüyü laboratuvara gönderir. Elde edilen alçı modelin laboratuvar tipi CAD/CAM tarayıcISı ile taranması sonucunda oluşturulan dijital ölçü üzerinde restorasyon tasarlanır ve kazıma ünitesinde üretilir. Elde edilen alt yapılar üzerine, tabakalama ya da ISIbasınç ile şekillendirme yöntemleri kullanılarak teknisyen tarafından üst yapılar hazırlanır. ${ }^{16}$ CEREC inLab (Sirona, GmbH, Bensheim, Almanya) ve Everest (KaVo Dental GmbH, Biberach, Almanya) sistemleri bu gruba örnektir (Resim 2) $)^{18}$.

c) Üretim merkezlerinde kullanılan merkezi üretim: Tarama ve tasarım aşamaları, üretim merkezlerine internet ağı ile bağlı olan dental laboratuvarlarda gerçekleştirilir. Üretim merkezlerine gönderilen dijital veriler doğrultusunda restorasyonlar üretilir ve elde edilen restorasyonlar laboratuvara gönderilir. Procera sistemi (Nobel Biocare, Göteborg, İsveç) bu gruba örnektir. ${ }^{16}$
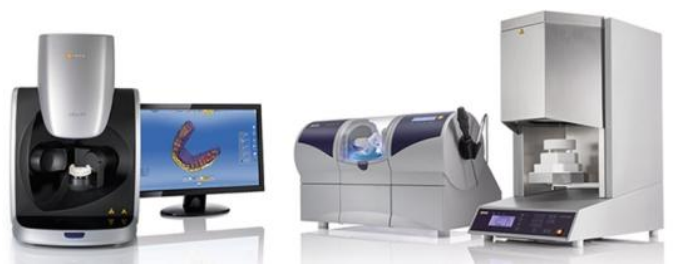

Resim 2. Laboratuvarda üretim gerçekleştiren Cerec InLab sisteminin ögeleri

CAD/CAM sistemlerinin avantajlarl; yüksek kalitede materyal kullanımına olanak sağladığı için dayanıklı restorasyonlar elde edilmesi, tabaka kalınlı̆ı gibi parametrelerin kontrol edilebilme kolaylığı, dijital arşivlemeye olanak vermesi, siman aralığı ile kenar bitim sınırı $\mu m$ düzeyinde belirlenebildiği için yüksek uyumluluğa sahip restorasyonların elde edilmesi, üretim basamaklarının ve üretim hatalarının azalması ile ekonomik ve hızı olmasıdır. ${ }^{19}$ Ayrıca CAD/CAM sistemi ile düz yüzeyli alt yapılar elde edilebileceği gibi, istenilen kalınlıkta, anatomik forma sahip alt yapılar da tasarlanabilir. Literatürde anatomik formlu zirkonya alt yapılar kullanıldığında, eşit kalınlıkta hazırlanan üst yapı seramiğinin alt yapı tarafından daha iyi desteklendiği ve bu şekilde üst yapı kırılmasının azaldığı belirtilmiştir. $^{20}$

CAD/CAM sistemlerinde kullanılabilen materyaller; krom-kobalt ( $\mathrm{Cr} / \mathrm{Co}$ ) alaşımları, titanyum, zirkonya, alümina, kompozit rezin, cam seramik ve hibrid kompozitlerden elde edilen, yüksek basınç altında gözeneksiz olarak üretilmiş olan prefabrike bloklardır. ${ }^{16}$

\section{Kopya Freze}

Kopya freze tekniğinin ana çalışma ilkesi, okuma ünitesine yerleştirilen modelajın kopyasının, sistemin diğer ünitesinde kazınarak üretilmesidir. Kopyalama bölümünde aşındırma özelliği olmayan özel tarayıcı uçlar modelaj üzerinde dolaşırken aynı anda kazıma ünitesinde yer alan özel frezler ve diskler seramik bloğu şekillendirir. ${ }^{15}$

Celay (Mikrona AG, Spreitenbach, İsviçre) ve Zirkonzahn (Steger, Ahrntal, İtalya) sistemleri kopyafreze tekniği ile çalışan sistemlerdendir (Resim 3$)^{21}$. 


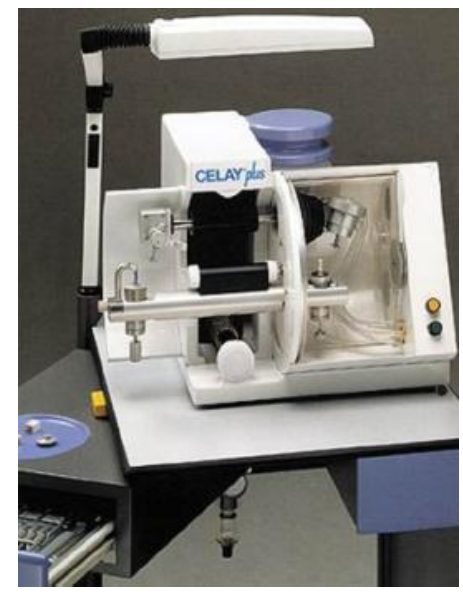

Resim 3. Celay sistemi

\section{EKLEME YÖNTEMİ}

Ekleme yöntemi, tabakaların birleştirilmesi ile 3 boyutlu verilerden model üretimi işlemi olarak tanımlanır. ${ }^{11}$ Elde edilen 3 boyutlu bilgisayar dosyası kesitlere ayrılır ve katı, sıvı veya toz gibi materyaller kullanılarak tabaka üzerine bir diğer tabakanın basılması ile model oluşturulur. ${ }^{11,22}$ Böylece eksiltme yönteminde frezeleme sonucu oluşan malzeme sarfiyatı engellenirken, hastaya özgü parçalar yüksek uyumda elde edilebilir. Üretim hızı, güvenilirlik ve ekonomik yönlerden geleneksel üretim tekniklerine göre avantajlı olduğu da bildirilmiştir. ${ }^{11}$

Ekleme yönteminden kaynağını alan hızı prototipleme (Rapid prototyping) yöntemi, ilave tabakalama tekniğini kullanarak modellerin hızı üretilmesi için mühendislik alanında 1980 yıllarında kullanılmaya başlanmışır. ${ }^{11,23}$ Biyomedikal sektöründe tanıtılması ile birlikte, cerrahi planlama, implantoloji, ortopedi ve maksilo-fasial protezler gibi çeşitli uygulamalarda da yer almaktadır. Günümüzde ekleme yöntemi, üretim öncesi hızlı prototipleme (rapid prototyping), tam üretimde hızı imalat (rapid manufacturing) ve kalıpgüdük üretimi gibi hızlı işleme (rapid tooling) teknolojilerini tanımlamaktadır. ${ }^{11}$ Hızlı prototipleme yöntemi ile polimer, metal ve seramik materyallerinden direkt olarak 3 boyutlu modeller elde edilebilir. ${ }^{11}$

Ekleme yöntemi teknolojileri; Stereolitografi (SLA), Selektif Lazer Sinterleme (SLS), Selektif Lazer Eritme (SLM), Tabakalı Nesne üretimi (Laminated Object Manufacturing- LOM), Kaynaklı Yükleme Modelleme (Fused Deposition Modelling- FDM) ve Mürekkep Baskı Tekniği (Inkjet Printing Techniques) olmak üzere çok çeşitlidir. ${ }^{11}$

\section{Stereolitografi (SLA)}

Charles W. Hull tarafindan 1986 yllında ilk kez tanitılan teknikte, istenilen şeklin 3 boyutlu modeli CAD programında oluşturulur ve model yazılım tarafından ince parçalara ayrılır. Konsantre ultraviyole ışını, tekne içindeki sIVı fotopolimeri tarayarak ilk tabakanın katı modeli elde edilir. Tabaka tabaka devam eden lazer tarama işlemi sonucunda, rezin tabakası her seferinde polimerize olarak veya çapraz bağlanarak diğer tabakalar oluşturulur ve model tamamlanır ${ }^{11}(\text { Resim } 4)^{11}$.

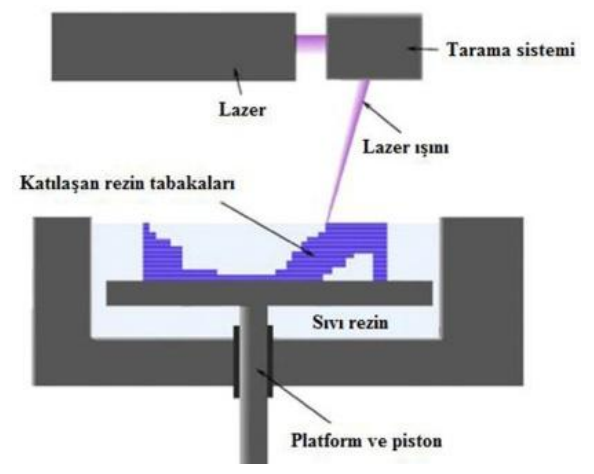

Resim 4. SLA sisteminin çalışma prensibi

SLA yöntemi, günümüz diş hekimliği ve tıp sektöründe yer almaktadır. Kranioplasti veya orbital taban gibi bölgelerde cerrahi işlemlerin planlanmasında SLA modelleri kullanıldığı gibi, cerrahi rehber, geçici kron-köprü protezlerinde ve kayıp mum tekniği için rezin modellerin üretiminde de SLA tekniği kullanılmaktadır. ${ }^{11}$

\section{Lazer Toz İşleme Teknikleri}

Lazer toz işleme esaslı ekleme yöntemleri; selektif lazer sinterleme (SLS) ve selektif lazer eritme (SLM) olarak sayılabilir. ${ }^{11,24}$

Selektif lazer sinterleme (SLS) yönteminde, tabaka şeklinde üst üste yığılan toz formundaki materyal, lazer ışını sonucunda oluşan ısı enerjisi ile birbirine bağlanır. İlk toz katmanının lazer ile sinterlenmesinden sonra, üretim bölümündeki piston yeni katman tabakası kadar aşağıya iner ve toz yatağının olduğu bölümden beslenerek yeni bir toz katmanı ile kaplanır. İstenilen model elde edilinceye kadar toz katmanlarının lazer ile sinterleme işlemi devam eder ${ }^{24}(\text { Resim } 5)^{24}$.

Selektif lazer eritme (SLM) yöntemi, selektif lazer sinterleme yöntemine benzerdir. Fakat sistemde kullanılan yüksek yoğunluklu enerji, toz partiküllerinin tamamen erimesine neden olur ve daha yüksek yoğunluğa sahip ürünler elde edilir. ${ }^{24}$ 


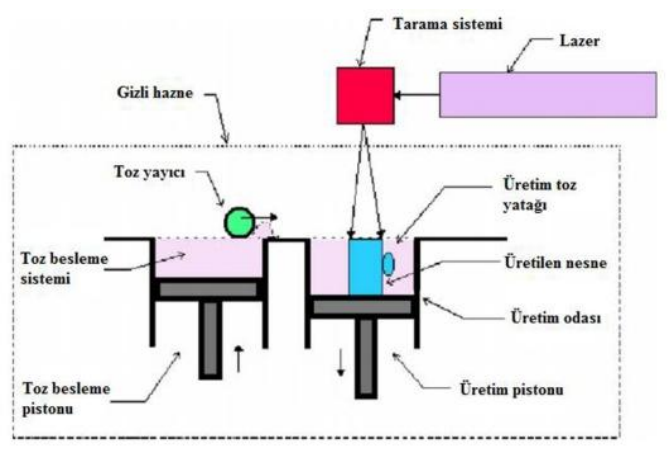

Resim 5. SLS sisteminin çalışma prensibi

Yöntemlerin sınırları hakkında ortak bir görüş olmaması nedeniyle kullanılan terminolojinin bazen karışık olduğu belirtilmiştir. Bu nedenle polimer ve seramik materyallerinden ürünlerin elde edilmesi genellikle selektif lazer sinterleme terimini ifade ederken, metaller için selektif lazer eritme terimi kullanılmaktadır. ${ }^{11}$

Lazer teknolojisi, ortopedide kemik analog implantları, dental implantlar, kron ve köprü protezleri ile bölümlü hareketli protezlerin alt yapılarının hazırlanmasında kullanım alanı bulmuştur. ${ }^{11}$

Tabakalı Nesne üretimi (Laminated Object Manufacturing (LOM)

Bu sistemde, kayan bir platform üzerinde ince bir levha ilerletilir ve ısıtılmış silindir ile alt katmana bağlanan levhanın dış hatları lazer tarafından kesilir. Her bir levhanın işlenmesinden sonra platform, bir katman kalınlığı kadar aşağıya iner. İstenilen 3 boyutlu nesne elde edilene kadar, herbir ince levha katmanın basınç ve Isı etkisi ile üst üste yapıştırılması işlemi devam eder. ${ }^{25}$

\section{Kaynaklı Yükleme Modelleme (Fused Deposition Modelling (FDM)}

Bu teknikte, ince filament şeklindeki termoplastik malzeme huni içindeki ısıtıcı tarafından ergime sıcaklığının üzerine çıkarıldığında bir katman oluşturacak şekilde dışarı akar. Bu katman sertleştikten sonra platform, sonraki katman kalınlığı kadar aşağıya iner ve materyal üretimi tamamlanana kadar ekstrüzyon işlemi devam eder. ${ }^{11}$

$\mathrm{Bu}$ teknikte akrilonitril bütadien stiren (Acrylonitrile butadiene styrene - ABS) polimeri, polikarbonat, polikaprolakton, polifenil sülfonlar ve suda çözünebilen materyaller model malzemesi olarak kullanılabilir. Hareketli ve çok parçalı sistemler, bu yöntem ile üretilebilir. ${ }^{11}$

\section{Mürekkep Baskı Tekniği (Inkjet Printing Techniques)}

Bu teknikte, püskürtülen renkli küçük mürekkep damlacıkları seramik süspansiyonuna yapışır. Mürekkep damlacıkları, ISı iletimi, UV ışık veya kimyasal reaksiyon gibi etmenlerle katı faza dönüşerek istenilen 3 boyutlu materyalin katmanları oluşturulur. Bir diğer yöntem ise, SLS/SLM tekniklerinde olduğu gibi lazer ile mürekkep damlacıklarının yapıştırıcı olarak kullanıımasıdır. ${ }^{11}$

Bu yöntem model eldesi, ortodontik braket rehber plağı, implant uygulanmasında kullanılan cerrahi rehberler ve uyku apnesinde kullanılan koruyucu plakların hazırlanmasında kullanılır. ${ }^{11}$

\section{ÜST YAPILARIN HAZIRLANMASI}

Üst yapı seramikleri, geleneksel olarak tabakalama yöntemiyle hazırlanabileceği gibi, alternatif olarak geliştirilen ISI ve basınç ile şekillendirme ve dosya bölme teknikleriyle de hazırlanabilir.

\section{Fırça Yöntemi ile Tabakalama Tekniği}

Geleneksel üst yapı hazırlama yöntemlerinden biri olan tabakalama tekniği, metal ve zirkonya alt yapılar üzerine uygulanabilir. Metal alt yapılarda, metal yansımasının önlenmesi amacıyla opak seramiğinin uygulanması ve fırınlanmasının ardından, üst yapı seramiği tabakalama yöntemi ile şekillendirilir. ${ }^{1}$ Zirkonya alt yapılarda ise, üst yapı seramiğinin bağlanma dayanımının arttırıması ve zirkonya opaklığının bir miktar maskelenmesi amacıyla çeşitli üretici firmalar tarafından genellikle astar materyali önerilir. Astar materyalinin önerilen programda ve sıcaklıklarda fırınlanmasının ardından üst yapı seramiği uygulanır. ${ }^{1}$

Tabakalama yönteminde seramik tozu ve özel likitinin spatül kullanılarak karıştırılması ile elde edilen seramik karışımı, kondansasyon yöntemi ile sinterlenen zirkonya alt yapı üzerine fırça yardımı ile uygulanır. Seramiğin şekillendirilmesi sırasında vibrasyon işlemi ile yüzeye çıkarılan hava boşlukları ve nem, kâğıt mendiller kullanılarak ortamdan uzaklaştırılır. Böylece seramik partikülleri birbirine yaklaştırılır ve kırık başlangıcından sorumlu olan porozite riski önlenerek materyalin dayanıklıı̆ı arttırılır. ${ }^{2,26}$ Ayrıca seramiğin fırınlanması sırasında seramik kitlesinin içinde bulunan suyun buharlaşması sonucunda seramik büzülmeye uğrar ve boyutsal değişim gösterir. Bu nedenle birçok seramik fırınlaması gerektiren tabakalama tekniğinde, büzülme miktarının karşılanması için restorasyon,

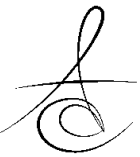


Atatürk Üniv. Diş Hek. Fak. Derg.

J Dent Fac Atatürk Uni

Cilt:25, Sayı: 1, Yıl: 2015, Sayfa: 135-143
KANAT ERTÜRK, DÜNDAR ÇÖMLEKOĞLU, ÇÖMLEKOĞLU, GÜNGÖR istenilen son formundan daha büyük olacak şekilde işlenmelidir. $^{2}$

Tabakalama tekniğinin başarısında birçok faktör etkili olduğu için, yöntemin hassas olduğu belirtilmektedir. Etkili olan bu faktörler; dental teknisyenin deneyimi, porselen karışımının homojenitesi, fırının kalibrasyonu, fırınlanma sayısı, pişim ve soğutma süreleridir. Ayrıca restorasyonun son şeklinin elde edilmesinde, fırınlanma sırasındaki boyutsal değişim nedeniyle frezeleme işleminin kullanılması, restorasyonların başarısını da olumsuz yönde etkilemektedir. ${ }^{27}$

Üst yapı seramiği uygun şekilde sinterize edildiğinde, yüzeyde eriyerek birbirlerine çeperlerinden bağlanan ve yaklaşık $25 \mu \mathrm{m}$ kalınlığında olan yoğun bir cam faz tabakası yer alır. Fırınlanma (sinterleme) sıcaklığının yüksek olması, restorasyonlarda detayların kaybolmasına ve daha yuvarlak hatların oluşmasına neden olur iken; fırınlanma sayısının fazla olması, seramikteki camsı fazın bozularak kristal faza dönüşmesi sonucunda geri dönüşümü olmayan ve kırılganlığın ve opasitenin artmasına neden olan devitrifikasyon olayına yol açar. ${ }^{28}$

\section{Isı ve Basınç ile Şekillendirme Tekniği}

Geleneksel tabakalama yönteminde oluşan üst yapı seramiğinin boyutsal değişimini önleyebilmek için, Isı-basınç ile şekillendirme tekniği geliştirilmiştir.

Isı-basınç ile şekillendirme tekniği, metal veya zirkonya alt yapılı restorasyonlarda kullanılabilir. Opak seramiği uygulanan metal alt yapılar veya sinterlenen zirkonya alt yapılar üzerine, üst yapının mum modelasyonu işlenerek restorasyonun son formu elde edilir. Alt yapı ve mum modelaj kombinasyonu revetman kalıba alınır ve ön ısıtma fırınında "kayıp mum tekniği" ile mum uzaklaştırılır. Daha sonra oluşan negatif boşluğa, bu teknik için özel olarak geliştirilen seramik materyali, özel bir pres fırınında basınç altında gönderilir ve restorasyon elde edilir. ${ }^{2}$

Bu tekniğin avantajı; tabakalama yöntemine göre üretimin daha hızlı ve kolay gerçekleşmesidir. Ayrıca ısı-basınç altında şekillendirme işlemi sırasında seramik materyali büzülmeye uğramadığı için restorasyonun kenar uyumunun daha iyi olduğu belirtilmektedir. ${ }^{29}$ Ancak mum modelajın bekleme süresi ve temizliği, döküm kanallarının uygun şekilde bağlanması, ön ısıtma fırınının sıcaklığı ve revetmanın bekleme süresi, döküm materyalinin kalitesi ve revetman artıklarının kumlama ile temizlenme sırasındaki hassasiyet gibi faktörler, bu tekniğin başarısında önemli rol oynar. ${ }^{10}$

\section{Dosya Bölme Tekniği}

CAD/CAM sistemindeki gelişmeler nedeniyle günümüz diş hekimliğinde kullanım alanı bulan "dosya bölme (file splitting)" tekniği, jenerik ismi olan "CADon" terimi (Ivoclar Vivadent, Schaan, Liechtenstein) ile tanıtılmıştır. Zirkonya alt yapılı restorasyonlarda, alt yapı ile aynı anda tasarlanan cam seramik üst yapıların CAD/CAM sistemi ile elde edilmesi yöntemidir. ${ }^{8,9}$

Dosya bölme (CAD-on ${ }^{\mathrm{TM}}$ ) yönteminde ilk aşama, CAD/CAM sistemindeki tarayıcı ile veri alma işlemidir. Preparasyonu tamamlanan dişler, komşu dişler, çevre yumuşak dokular, karşıt ark ve okluzyonda karşıt arkın durumu optik okuyucu ile taranarak dijital ölçü elde edilir. Dijital ölçü alımı, ağız içi kayıt alabilen özel optik okuyucu kullanılarak direkt olarak yapılabildiği gibi, elde edilen alçı model üzerinde laboratuvar tasarım yazılım programı (InEos Blue, Sirona Dental Systems, GmbH, Bensheim, Almanya) kullanılarak indirekt olarak da gerçekleştirilebilir. ${ }^{16}$ Yazılım programında, bilgisayar ortamında oluşturulan 3 boyutlu model üzerinde, restorasyonun bitim sınırı ve giriş yolu belirlenir (Resim 6$)^{10}$. CAD-on yöntemi için "multilayered" seçeneği işaretlenir ve istenilen diş formuna göre zirkonya alt yapı ve seramik üst yapı aynı anda birbiriyle uyumlu bir şekilde tasarlanır $\left(\right.$ Resim 7) ${ }^{10}$. CAD/CAM sistemi için hazırlanan zirkonya bloklar kullanılarak kazıma ünitesinde elde edilen alt yapı, sinterizasyon işlemi sonrasında ağızda kontrol edilir. Alt yapı ile aynı anda tasarlanan üst yapı, hazır seramik bloklar kullanılarak kazıma ünitesinde elde edilir ve sinterlenen zirkonya alt yapı ile olan uyumu kontrol edilir (Resim 8) ${ }^{10}$. Dosya birleştirme yöntemi ile hazırlanan alt yapı ve üst yapılar, farklı firmaların önerileri doğrultusunda birleştirilerek restorasyonun son formu elde edilir. ${ }^{8,10}$

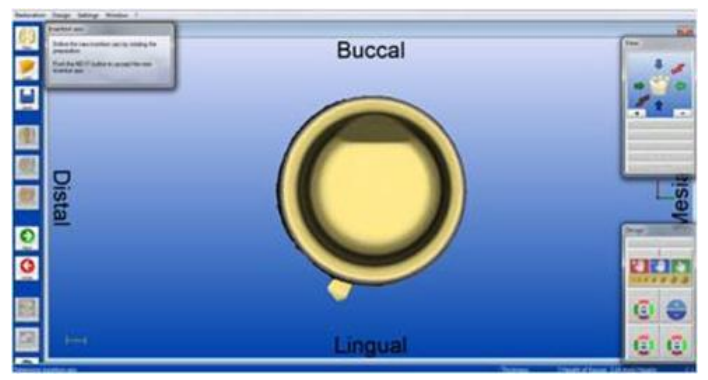

Resim 6. Restorasyonun bitim kenarlarının ve giriş yolunun belirlendiği digital ölçü 


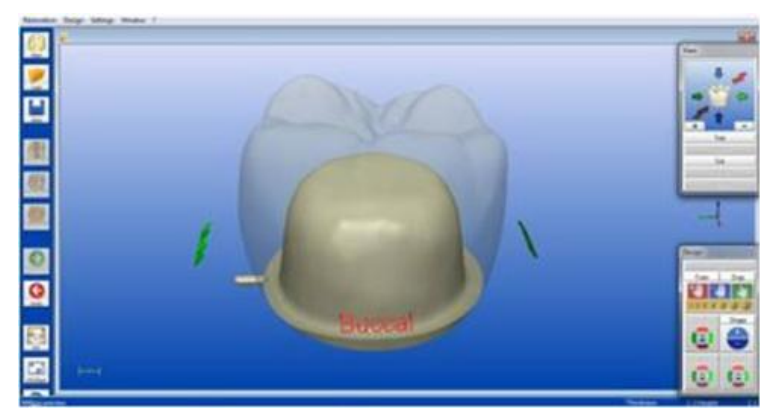

Resim 7. Dosya bölme tekniğine göre restorasyonun tasarlanması
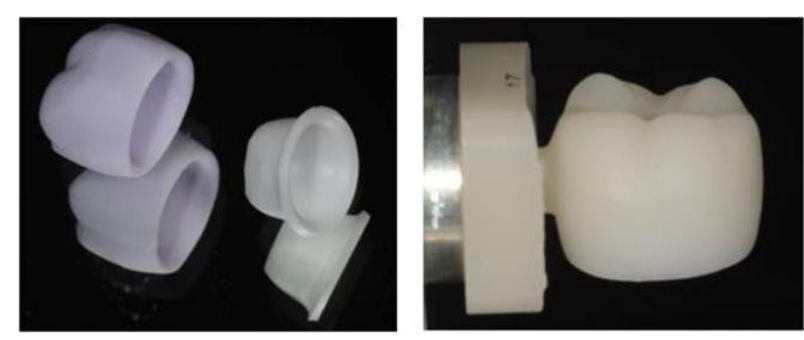

Resim 8. Seramik bloktan üst yapının kazınması

Farklı üretici firmalar tarafından geliştirilen dosya bölme yöntemlerinde, üst yapı seramiğinin içeriği, alt yapı-üst yapı birleştirilmesinde kullanılan ara yüz birleştirme materyali ve yöntemi farkllık gösterir. Örneğin zirkonya alt yapı üzerine (IPS e.max ZirCAD, Ivoclar Vivadent, Schaan, Liechtenstein) lityum disilikat ile güçlendirilmiş üst yapı seramiği (IPS e.max CAD, Ivoclar Vivadent) kullanılan sistemde, birleştirici arayüz materyali olarak özel olarak geliştirilen tiksotropik yapıdaki cam seramik (IPS e.max CAD Crystall./Connect, Ivoclar Vivadent) kullanilır. Özel titreşim cihazında (Ivomix, Ivoclar Vivadent) yaklaşık 10 saniye bekletilerek istenilen kıvama gelen arayüz materyali (Resim 9A, 9B) ${ }^{10}$, üst yapı materyalinin iç yüzeylerine uygulanır (Resim 9C) ${ }^{10}$ ve sinterlenen zirkonya alt yapı, doğru konumda olmasına dikkat edilerek monosilikat yapıdaki üst yapı porseleni içine yerleştirilir (Resim 9D-F) ${ }^{10}$. Üst yapı seramiğinin lityum disilikat forma dönüşerek dayanıklılı̆ının arttırıması ve arayüz yapıştırııı materyalin kristalizasyonu için, üretici firmanın önerileri doğrultusunda uygun programda kristalizasyon fırınlaması gerçekleştirilir. Glazür işlemi uygulanan restorasyonlar tamamlanır. 8,9
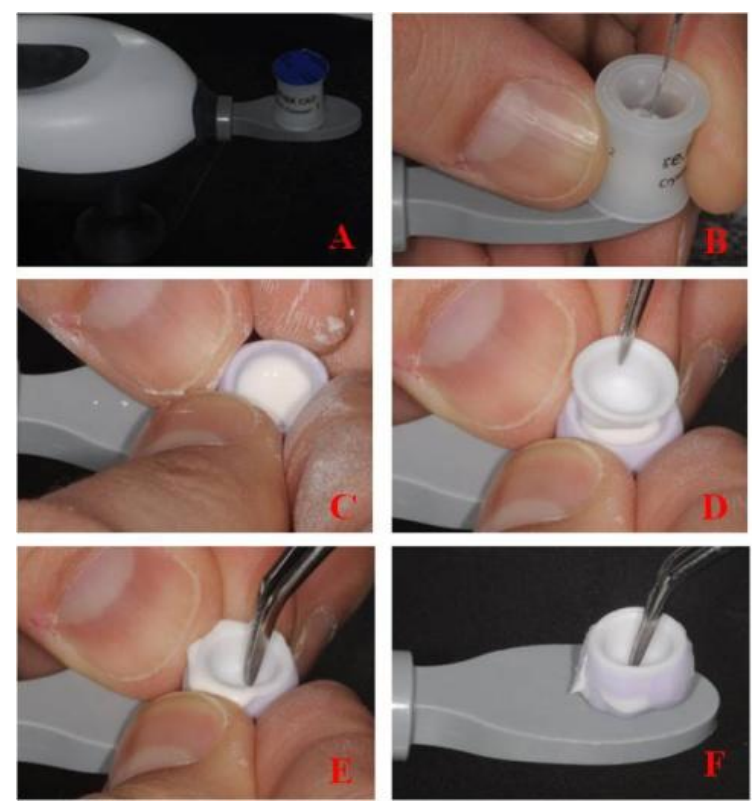

Resim 9. Zirkonya alt yapı ve cam seramik üst yapının tiksotrofik özellikteki özel cam seramik ile birleştirilmesi

Zirkonya alt yapı (In-Ceram YZ, VITA Zahnfabrik, Bad Säckingen, Almanya) ve feldspatik esaslı seramik (Vita Mark II, VITA Zahnfabrik) kombinasyonu kullanılan sistemde ise kazıma ünitesinde elde edilen üst yapılar üzerine glazür porseleni uygulanır ve uygun programda sinterize edilir. Sinterlenen zirkonya alt yapı ve glazür işlemi uygulanan üst yapı, firma tarafindan önerilen rezin kompozit (Panavia F 2.0, Kuraray Medical Inc., Japonya) ile birleştirilir (Resim $10)^{10}$. Simanın ışık ile polimerizasyonu ve birleşim hattının cilalanması sonrasında restorasyonlar tamamlanır. ${ }^{10,30}$
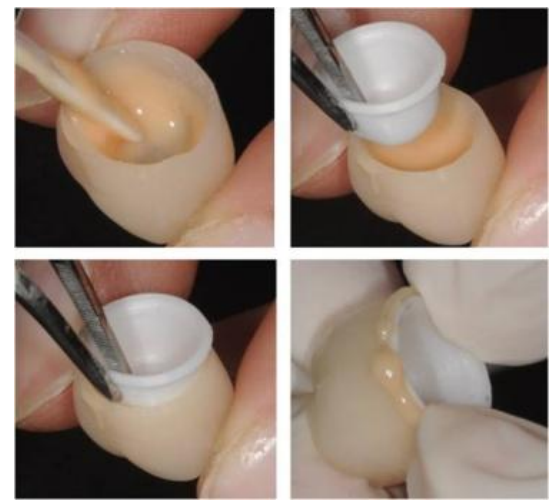

Resim 10. Zirkonya alt yapı ile feldspatik seramiğin rezin kompozit ile birleştirilmesi

Diğer bir firmada ise, restorasyonun tasarı-

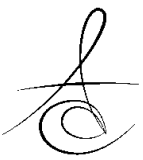


Atatürk Üniv. Diş Hek. Fak. Derg.

J Dent Fac Atatürk Uni

Cilt:25, Sayı: 1, Yıl: 2015, Sayfa: 135-143
KANAT ERTÜRK, DÜNDAR ÇÖMLEKOĞLU, ÇÖMLEKOĞLU, GÜNGÖR mına uygun bir şekilde kazıma ünitesinde elde edilen zirkonya alt yapı (Lava ${ }^{\mathrm{TM}}$ Zirconia, 3M ESPE, Seefeld, Almanya) ve cam seramik üst yapı (Lava ${ }^{\mathrm{TM}}$ DVS, 3M ESPE), özel bir porselen (Lava ${ }^{\mathrm{TM}}$ DVS Fusion Porcelain, $3 M$ ESPE) ile birleştirilir ve üretici firmanın önerileri doğrultusunda sinterize edilir. Karakterizasyon ve glazür işlemlerinden sonra restorasyonlar tamamlanır. ${ }^{31}$

Dosya bölme (CAD-on) yönteminde kullanılan hazır seramik bloklar, seramik tozlarının basınç altında sıkıştırılması ile elde edildiği için porozite içermez ve yüksek dayanıklıığa sahiptir. Bu yöntemde seramik materyali boyutsal değişimine uğramadığı için restorasyonun direkt olarak son şekli elde edilir. ${ }^{9,32}$ Ayrıca CAD/CAM sistemi ile karşıt ark ölçüsünün ve kapanış kaydının alınabilmesi, istenilen okluzal temaslara sahip restorasyonların tasarlanarak üretilebilmesine olanak tanır. ${ }^{8}$

CAD/CAM sisteminin yüksek duyarlılıkta çalışma ilkesinden kaynaklanan avantajı yanı sıra dosya bölme yönteminin diğer avantajları; laboratuvar aşamalarının ortadan kaldırılması ile restorasyon üretimi için gereken sürenin azaltılması, üst yapının klinikte kolay bir şekilde hazırlanması ve restorasyonun aynı gün içinde tek seansta bitirilebilmesidir. ${ }^{33}$ Ayrıca, CAD/CAM sistemlerinde restorasyonlar, dijital ortamda tasarlanarak kazıma ünitesinde elde edildiği için üst yapı seramiğinin fırınlanma sıcaklığı, soğuma hızı, seramiğin işlenmesi sırasında oluşabilecek poroziteler, teknisyenin deneyimi, fırınlama sırasında oluşabilecek büzülme ve artık stresler gibi alt yapı ile üst yapı arasında bağlantı dayanıklıığının azalmasına neden olabilecek etkenler de ortadan kaldırılır. ${ }^{34}$

\section{SONUÇ}

Uzun süreli klinik başarıya sahip restorasyonların elde edilmesinde, alt yapı ve üst yapı hazırlama yöntemleri ile kullanılan materyallerin özellikleri önemli rol oynamaktadır. Günümüz diş hekimliğinde, daha az hata oranı içeren restorasyonların yüksek dayanıma sahip materyallerden elde edilmesine izin verilmektedir. CAD/CAM sistemindeki gelişmeler doğrultusunda, geleneksel alt yapı ve üst yapı hazırlama yöntemlerine ek olarak geliştirilen dosya bölme (File splitting- CAD-on) yönteminin kullanımı gün geçtikçe artmaktadır. Gelişen teknoloji ile birlikte eksiltme yöntemlerinin yanı sıra, ilave tabakalama prensibini benimseyen ve malzeme sarfiyatını önleyen ekleme yöntemleri de günümüz diş hekimliğine tanıtılmıştır. Güncel alt yapı hazırlama yöntemleri, üst yapı hazırlama yöntemleri ve kullanılan materyalleri ele alan bu derleme çalışması, klinik ve deneysel çalışmalara yön vermesi açısından önem taşımaktadır.

\section{KAYNAKLAR}

1. Raigrodski AJ. Contemporary materials and technologies for all-ceramic fixed partial dentures: a review of the literature. J Prosthet Dent 2004;92:557-62.

2. Ishibe $M$, Raigrodski $A J$, Flinn $B D$, Chung $K H$, Spiekerman C, Winter RR. Shear bond strengths of pressed and layered veneering ceramics to highnoble alloy and zirconia cores. J Prosthet Dent 2011;105:29-37.

3. Zarone F, Russo S, Sorrentino R. From porcelainfused-to-metal to zirconia: clinical and experimental considerations. Dent Mater 2011;27:83-96.

4. Çömlekoğlu $M E$, Dündar $M$, Özcan $M$, Güngör $M A$, Gökçe $B$, Artunç $C$. Evaluation of bond strength of various margin ceramics to a zirconia ceramic. J Dent 2008;36:822-7.

5. Kelly JR, Denry I. Stabilized zirconia as a structural ceramic: an overview. Dent Mater 2008;24:289-98.

6. Schmitter M, Mueller D, Rues S. Chipping behaviour of all-ceramic crowns with zirconia framework and CAD/CAM manufactured veneer. J Dent 2012;40:154-62.

7. Uludamar A, Aygün Ş, Kulak Özkan Y. Zirkonya esaslı tam seramik restorasyonlar. Atatürk Üniv Diş Hek Fak Derg 2012;5:132-41.

8. Beuer F, Schweiger J, Eichberger M, Kappert HF, Gernet W, Edelhoff D. High-strength CAD/CAMfabricated veneering material sintered to zirconia copings - A new fabrication mode for all-ceramic restorations. Dent Mater 2009;25:121-8.

9. Kanat $B$, Çömlekoğlu $M E$, Çömlekoğlu Dündar $M$, Şen BH, Özcan M, Güngör MA. Effect of Various Veneering Techniques on Mechanical Strength of Computer-Controlled Zirconia Framework Designs. J Prosthodont 2014;23:445-55.

10. Kanat B. Farklı yöntemlerle üst yapıları hazırlanan zirkonya destekli kron restorasyonlarının kırılma dayanımlarının araştırıması. Ege Üniversitesi Sağlık Bilimleri Enstitüsü, Protetik Diş Tedavisi Anabilim Dalı Doktora Tezi, 2013. 
Atatürk Üniv. Diş Hek. Fak. Derg.

J Dent Fac Atatürk Uni

Cilt:25, Sayı: 1, Yıl: 2015, Sayfa: 135-143
KANAT ERTÜRK, DÜNDAR ÇÖMLEKOĞLU, ÇÖMLEKOĞLU, GÜNGÖR
11. Van Noort R. The future of dental devices is digital. Dent Mater 2012;28:3-12.

12. Asgar K. Casting metals in dentistry: past - present - future. Adv Dent Res 1988;2:33-43.

13. Höland, AW, Strub JR, Scharer P. Metal ceramic and all-Porcelain restorations: Current considerations. Int J Prosthodont 1989;2:13-26.

14. Strub JR, Rekow ED, Witkowski S. Computer-aided design and fabrication of dental restorations: current systems and future possibilities. J Am Dent Assoc 2006;137:1289-96.

15. Mörmann W, Bindle A. All-ceramic chair- side computer-aided design/computer-aided machining restorations. Dent Clin North Am 2002;46:405-26.

16. Beuer F, Schweiger J, Edelhoff D. CAD/CAM in dentistry: New Materials and Technologies. Dentistry 2010;2.

17. Mörmann WH. The evolution of the CEREC system. J Am Dent Assoc 2006;137:7S-13S.

18. $C A D / C A M$ solutions for the dental laboratory. inLab. The art of innovative dental technology. http://www.sirona.com/en/epaper-inlab/.

19. Mehl A, Hickel R. Current state of development and perspectives of machine-based production methods for dental restorations. Int J Comput Dent 1999;2:9-35.

20. Guess PC, Bonfante EA, Silva NR, Coelho PG, Thompson VP. Effect of core design and veneering technique on damage and reliability of Y-TZPsupported crowns. Dent Mater 2013;29:307-16.

21. Luthardt VR, Rudolph $H$, Sandkuhl O, Walter M. Aktuelle CAD/CAM-Systeme zur Herstellung von keramischem Zahnersatz Einleitung.

http://www2.spitta.de/Zahnmedizin/Aktuelles/Druckan sicht/134_index+M54caf1a9105.html.

22. Goiato MC, Santos MR, Pesqueira AA, Moreno A, dos Santos DM, Haddad MF. Prototyping for surgical and prosthetic treatment. J Craniofac Surg 2011;22:914-7.

23. Chang PSH, Parker TH, Patrick CW Jr, Miller MJ. The accuracy of stereolithography in planning craniofacial bone replacement. J Craniofac Surg 2003;14:164-70.

24. Santos EC, Shiomi M, Osakada K, Laoui T. Rapid manufacturing of metal components by laser forming. International Journal of Machine Tools and Manufacture 2006;46:1459-68.

25. Çelik İ, Karakoç F, Çakır MC, Duysak A. Hızlı prototipleme teknolojilerive uygulama alanları.
Dumlupınar Üniversitesi Fen Bilimleri Enstitüsü Dergisi 2013;31:53-70.

26. Stawarczyk B, Özcan M, Roos M, Trottmann A, Sailer I, Hämmerle CHF. Load-bearing capacity and failure types of anterior zirconia crowns veneered with overpressing and layering techniques. Dent Mater 2011;27:1045-53.

27. Liu $Y$, Feng $H$, Bao $Y$, Qiu $Y$, Xing $N$, Shen $Z$. Fracture and interfacial delamination origins of bilayer ceramic composites for dental restorations. J Eur Ceram Soc 2010;30:1297-305.

28. Fairhurst CW, Hashinger DT, Twigs SW. The effect of thermal history on porcelain expansion behavior. J Dent Res 1989;68:1313-8.

29. Eisenburger M, Mache T, Borchers L, Stiesch $M$. Fracture stability of anterior zirconia crowns with different core designs and veneered using the layering or the press-over technique. Eur J Oral Sci 2011;119:253-7.

30. Kurbad A. Digital veneering--manufacturing computer-generated veneers with the CAD-on technique. Int J Comput Dent 2011;14:255-71.

31. LAVA ${ }^{\mathrm{TM}}$ DVS Digital veneering system. Full Contour Digital Crown.

http://multimedia.3m.com/mws/mediawebserver?mws Id=66666UF6EVsSyXTtnxTt4XMtEVtQEVs6EVs6EVs 6E666666--\&fn=lava_dvs_lab_brochure.pdf.

32. Miyazaki T, Hotta $Y$, Kunii J, Kuriyama S, Tamaki Y. A review of dental CAD/CAM: current status and future perspectives from 20 years of experience. Dent Mater J 2009;28:44-56.

33. Lorenzoni FC, Martins LM, Silva NR, Coelho PG, Guess PC, Bonfante EA, Thompson VP, Bonfante G. Fatigue life and failure modes of crowns systems with a modified framework design. J Dent 2010;38:626-34.

34. Sundh A, Molin M, Sjögren G. Fracture resistance of yttrium oxide partially-stabilized zirconia allceramic bridges after veneering and mechanical fatigue testing. Dent Mater 2005;21:476-82.

\section{Yazışma Adresi}

Burcu KANAT ERTÜRK

Kocaeli Üniversitesi,

Diş Hekimliği Fakültesi

Protetik Diş Tedavisi Anabilim Dalı,

Başiskele 41190 Kocaeli

e-mail:burcukanat@hotmail.com 